\title{
The Exhibition as an "urban thing”
}

\author{
Mark Dorrian, Adrian Hawker
}

Metis: Mark Dorrian + Adrian Hawker

On The Surface

Arkitektskolen Aarhus, Denmark: 10 October - 14 November 2014

Edinburgh College of Art, Scotland, UK: 27 March - 6 April 2015

Assistants: Aikaterini Antonopoulou and Richard Collins

Curator: Karen Kjærgaard

Floor textile manufactured by Ege, Denmark

What wo What would it be to construct an exhibition that worked as a "thing" - and more particularly as an "urban thing", with all the connotations of density, encounter, transformation and mediation that the term might imply? Bruno Latour's influential essay "Why has critique run out of steam?" gives us some clues. In this text, he discusses the relation between what he describes as "matters of fact" and "matters of concern". While the two phrases might at first sight appear to sit in opposition to one another, Latour characterises the former as a specific, reduced, case of the latter: "Matters of fact are only very partial and, I would argue, very polemical, very political renderings of matters of concern and only a subset of what could also be called states of affairs"(Latour 2004:232).

Developing his argument via Heidegger, Latour goes on to introduce the distinction between "objects" and "things", categories that he associates respectively with his two matters of fact and concern. So, where objects are categorised as "matters of fact" (determined, decided, mastered, inert), things are instead sites where complex "gatherings" of relations occur. Latour cites the by now well-known etymology that links the word "thing" to an assembly or parliament - thus his comment that a "thing is, in one sense, an object out there and, in another sense, an issue very much in there, at any rate, a gathering"(Latour 2004: 233). It is not the case, however - and this is in keeping with Latour's earlier description of facts as particularised instances of more expansive concerns - that some entities are, in themselves, "objects" and some are "things". Instead, he seems to tell us, they are all things, and we should understand them as such, but we frequently - perhaps usually - misrecognise them as objects. The object/ thing distinction thus comes to be about the kind of relations we have with entities and our attitude to them, or better, the way we attend to them.

At the same time, however, Latour's argument implies that some things, in the way they are given to us in complexity, are more resistant to being resolved into objects than others. So, at one point, drawing on the work of the philosopher of science Ian Hacking, he gives the example of a "banal rock" (an object) as opposed to dolomite (a thing). "The first", he writes, "can be turned into a matter of fact, but not the second. Dolomite is so beautifully complex and entangled that it resists being treated as a matter of fact" (Latour 2004: 234). Another example he puts forward is the spaceshuttle-Columbia disaster, which he characterises as the transformation of something that had previously appeared to be an object into something that could only be understood as a thing: a catastrophic unfolding of relations that already existed within and structured the vessel, resulting in a field of debris that could never be mistaken for the kind of entity that we normally describe as an "object".

On The Surface was a retrospective exhibition of work by Metis, designed for the gallery of the Arkitektskolen Aarhus in Denmark, which ran from 10 October to 14 November 2014. Seven projects, spanning twelve years, were shown in it, stretching from Metis's 2002 book, Urban Cartographies, to a competition project developed in 2014 for a spa hotel in Liepaja, Latvia. Any exhibition that involves a number of works is of course inevitably a gathering of a complex kind that brings together not only exhibits, within which multiple relations are already enfolded, but also people (producers, curators, technicians, visitors, etc.). However, this is not to say that this 'thingliness' remains in evidence, for more often than not it is systematically suppressed - for example by curatorial approaches that take as their imperative the pre-eminence of the pristine exhibited object.

In the case of 'On the Surface', we sought to articulate the 'thingliness' of the exhibition and make it legible through establishing a display strategy whereby all that was shown would exist on horizontal, as opposed to vertical, surfaces. In the first instance, this meant engaging the overall 
space of the gallery with a large floor drawing, which was manufactured for the exhibition as a textile surface. This established a zone, a kind of mat, within the building that acted as a space of encounter and gathering place for both projects and visitors to the exhibition. Upon this zone, not only did people interact with each other and the displayed work, but also the projects themselves encountered one another in new and reconfigured ways. It was crucial for the exhibition idea that visitors could step onto the floor drawing and be visually immersed in its laterally spreading constructed field, thereby losing the kind of distanced relation that would allow the object of vision to be optically encompassed and settled.

The floor drawing was composed of representations of the seven projects, deriving from different media - some photographic, some drawing-based, some digitally generated. Stripped as they were of stable reference points (common lines of projection, scale relations, etc.) that would allow them to solidify as a "ground", they came to interact with one another as an array of contingent forms. Here the fluctuation between disparate scales was echoed in the interplay of effects of surface and depth that was produced the sense of a flatness that was, at the same time, experienced as a swarming, mobile, and thick space. This for us recalled baroque representations of the heavens, such as those of Andreas Cellarius, whose atlas is referred to in the Micro-Urbanism project that was exhibited. Situated in this force field, visitors were invited to navigate, explore and play with its constitutive array of relations. As Claudia Carbone has written of walking on this surface in a recently published review of the exhibition: "This action ... of following the drawing on the ground, enables the erasure of the specific time/place chronotopes of the seven exhibited projects, allowing new itineraries to be drawn through the crossing of this complex context" (Carbone 2015: 107109, 107).

One effect of the floor drawing was to spatially distribute the projects in the gallery space, establishing territories that were then occupied by display tables, each holding three sheets of drawings within a double layer of glass, on top of which was also positioned a model. These, acting as anchors within the large-scale field, set up smaller and more intimate spaces that demanded a mode of closely situated reading. Here the eye was drawn toward the elevated surface of the table, concentrating vision while at the same time leaving open a peripheral zone that opened onto the expanses of the floor drawing below.

Because everything in the exhibition existed on a horizontal surface, with the tabletop height calibrated to a datum line of text running around the gallery wall, the experience of it radically transformed with shifts in height and angle of vision. When the eye was lowered to the level of the tabletops, the graphic surfaces tended to disappear, producing a reading of the exhibition as an arrangement of island-like models constellated within the space of the gallery. As the eye rose, however, and the viewing angle increased, the volumetrics of the models and the tables progressively collapsed, until they were fully absorbed into the complex differentials of the graphic surface.

Key to the exhibitionary strategy that motivated 'On the Surface' was the idea of an approach to each project that dispersed what would otherwise appear as an object through an array of spaces, scales and representational modalities that sat in a "flat", non-hierarchical relation to one another and could never coalesce into a single, privileged artifact. Under these conditions, none of the projects on display were ever identifiable in an exhaustive way with a specific location or object in the exhibition. Instead, the projects emerged as things - which is to say, as gatherings that participated in, and interacted with, the larger complex gathering of the "urban thing", as it was constituted by the exhibition itself. 


\section{Figures:}

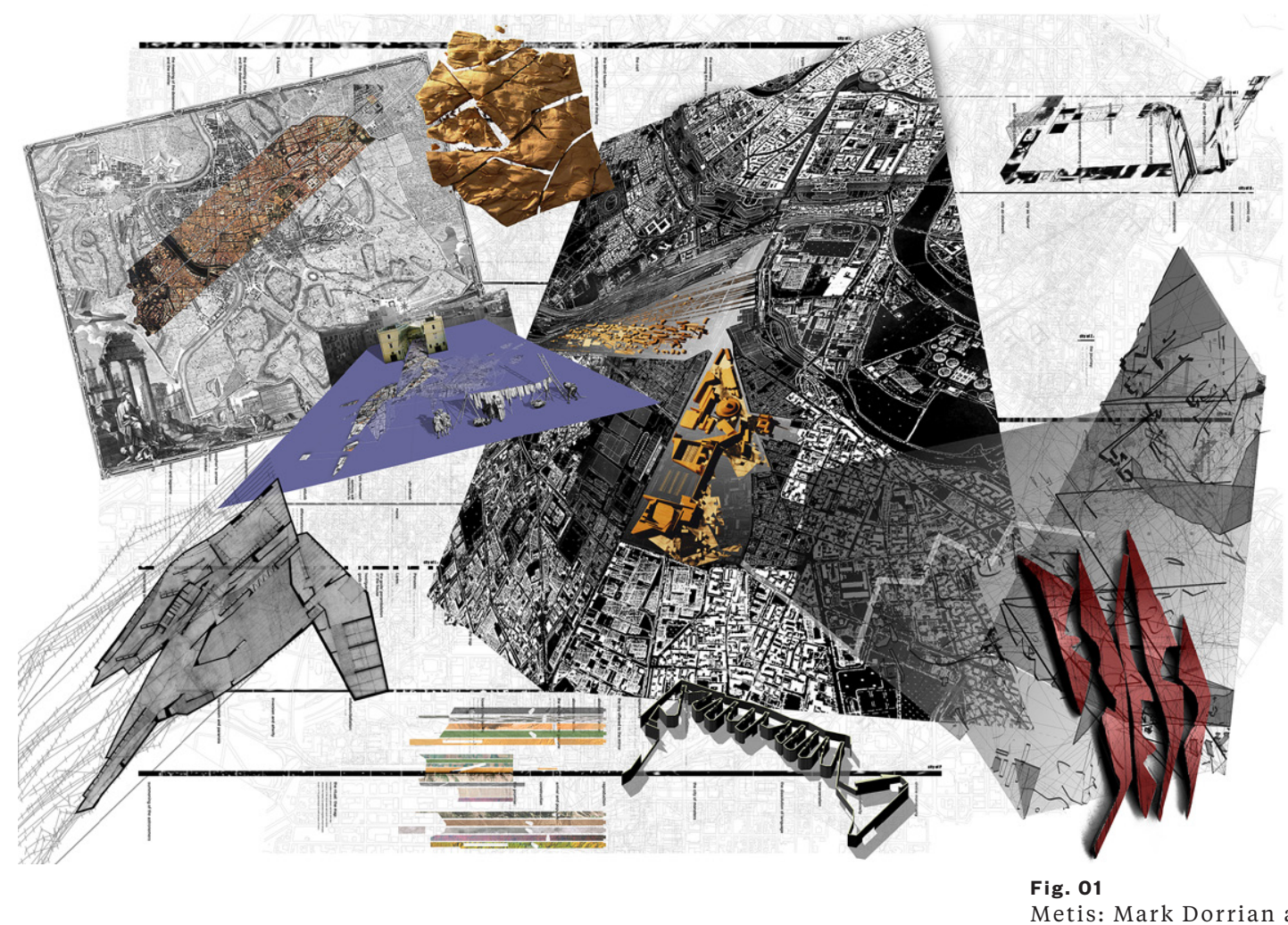

Metis: Mark Dorrian and Adrian Hawker, On the Surface,[Plan of floor drawing]

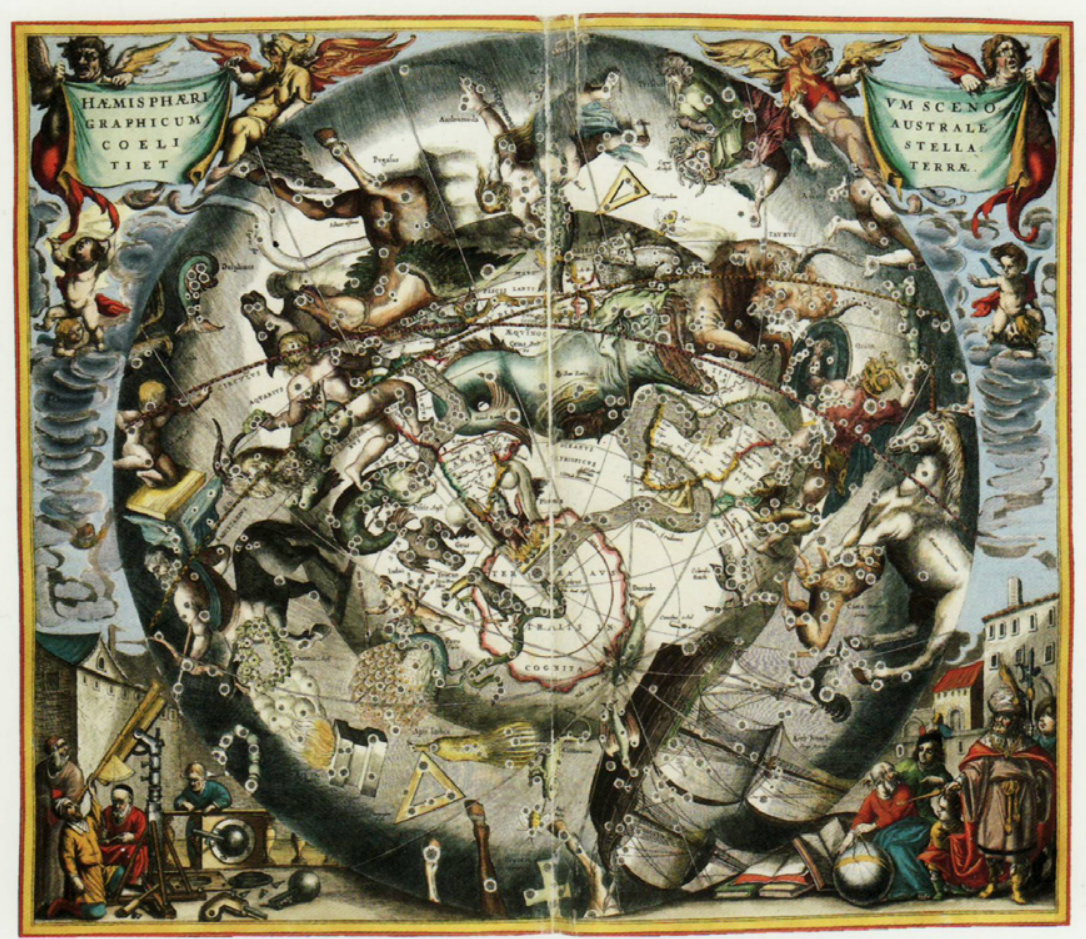

Fig. 02

Andreas Cellarius, The Southern Hemisphere and Its Heavens [From the Atlas Coelestis seu Harmonia Macrocosmica (Amsterdam, 1660)] 


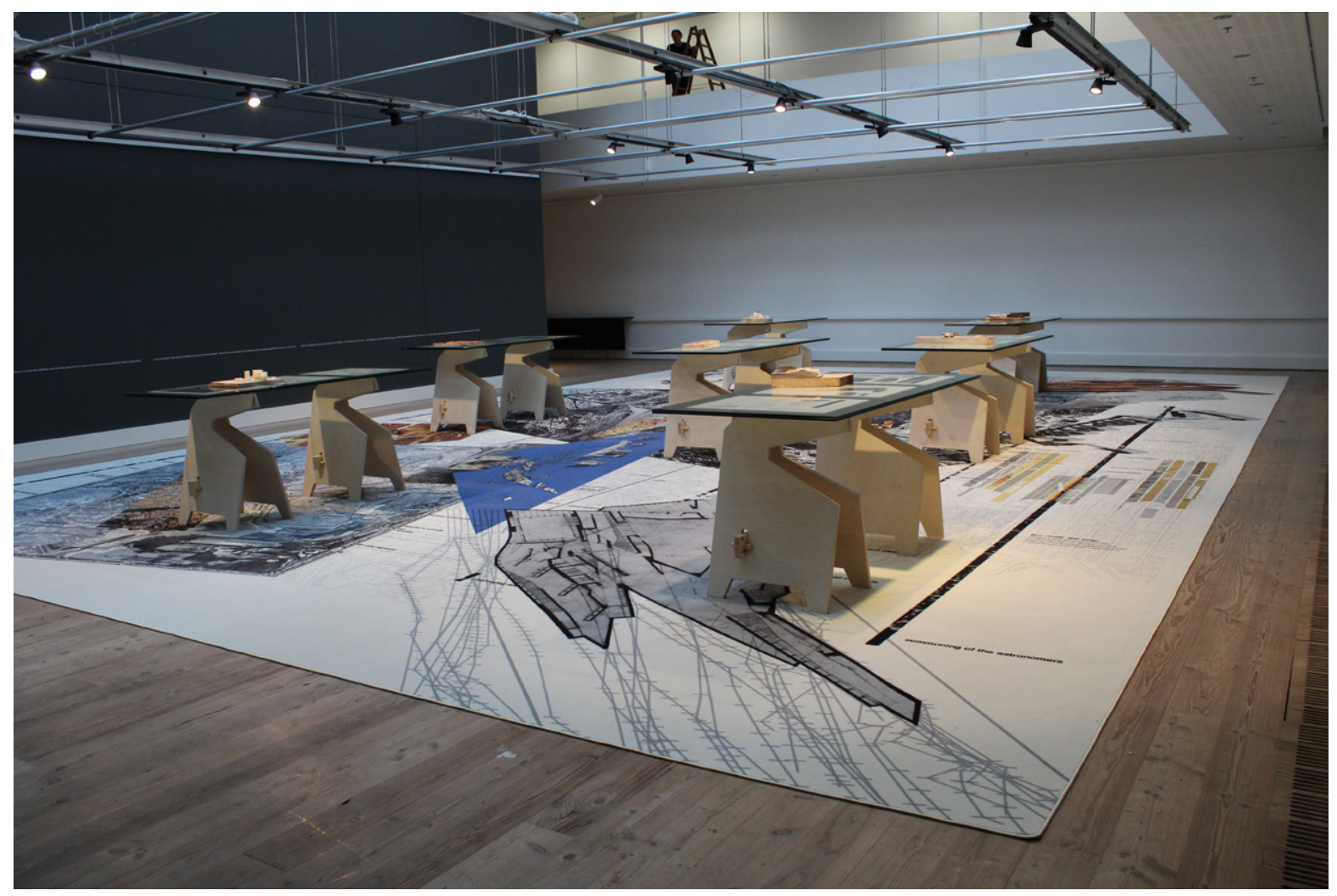

Fig. 03

Metis: Mark Dorrian and Adrian Hawker, On the Surface [Low level view]

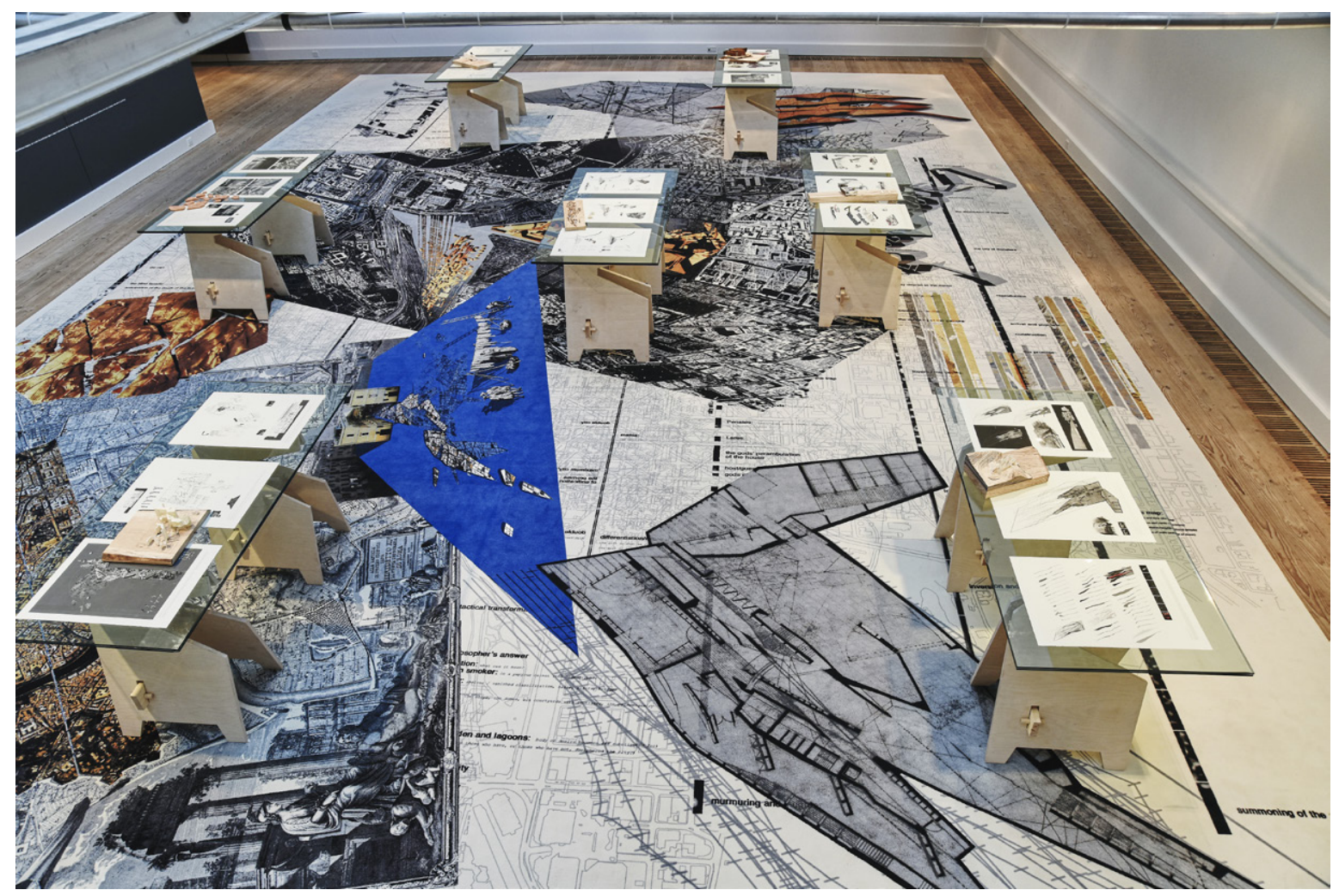

Fig. 04

Metis: Mark Dorrian and Adrian Hawker, On the Surface [Territories and tables] 

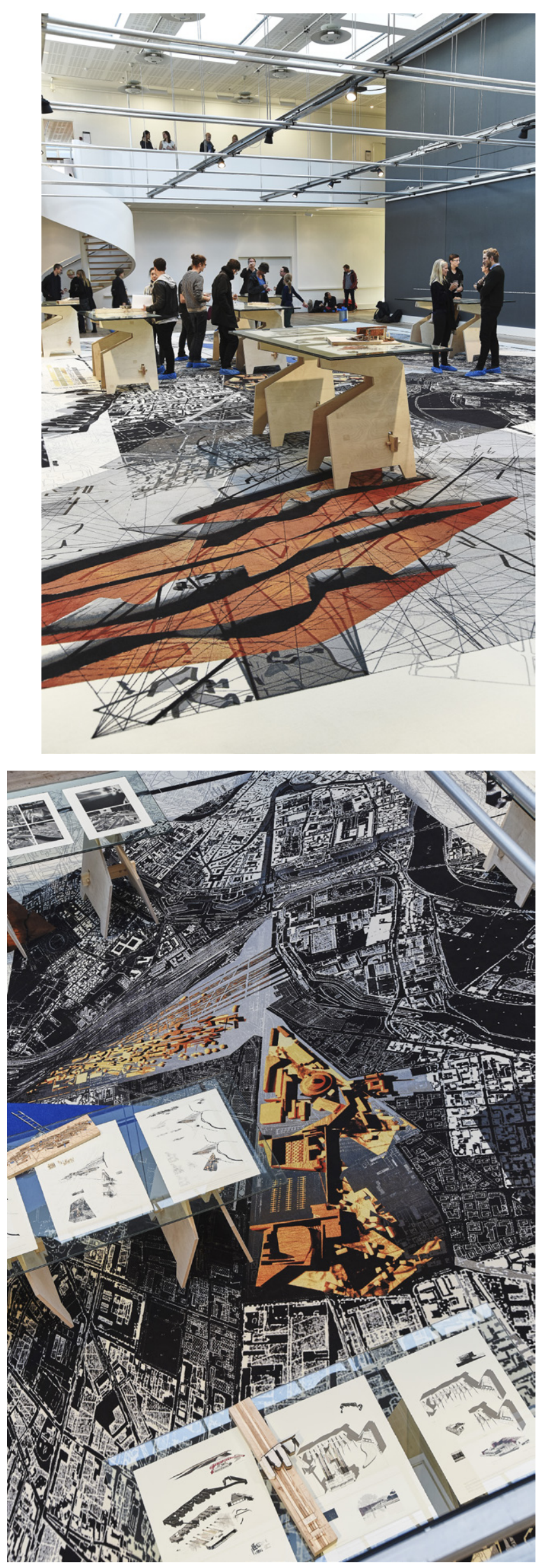

Metis: Mark Dorrian and Adrian Hawker, On the Surface [View with Egyptian Museum project in foreground]

\section{Fig. 06}

Metis: Mark Dorrian and Adrian Hawker, On the Surface [View from balcony] 

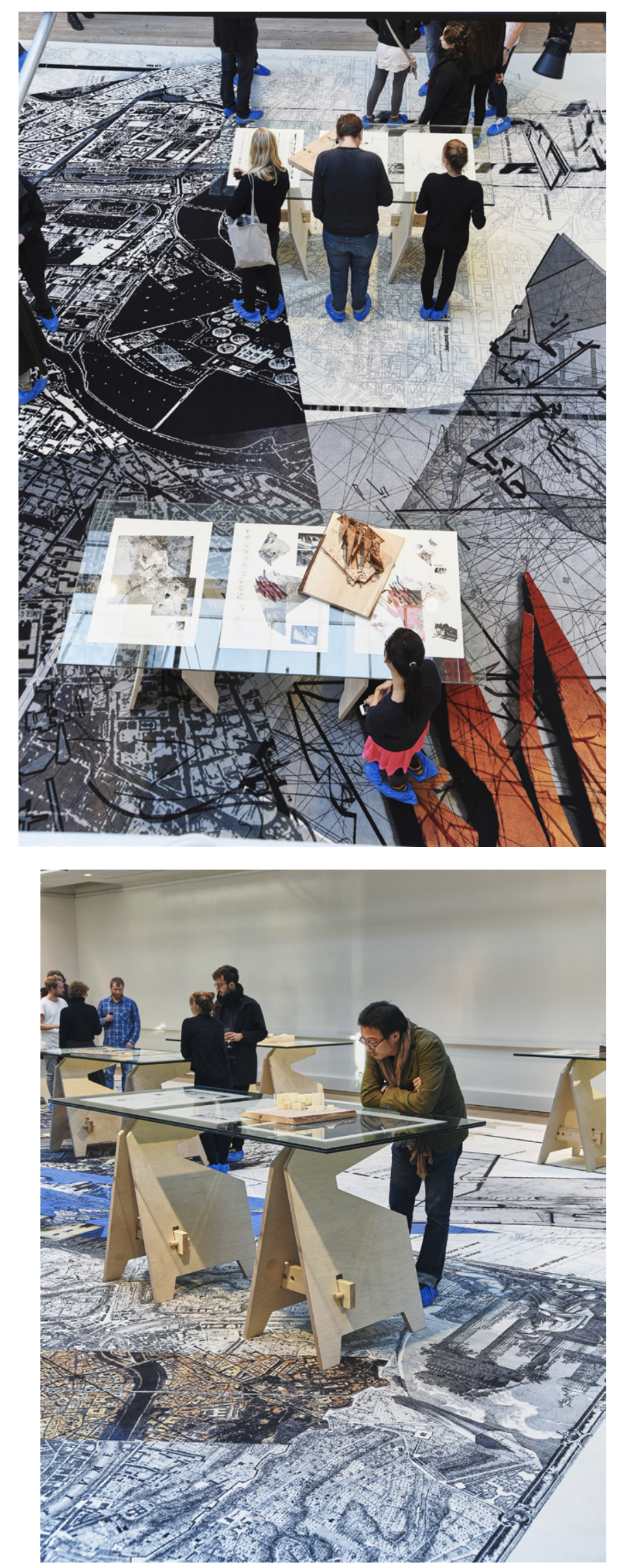

Fig. 07

Metis: Mark Dorrian and Adrian Hawker, On the Surface [View from balcony]

Fig. 08

Metis: Mark Dorrian and Adrian Hawker, On the Surface [Cabinet of the City, Municipal Art Gallery, Rome] 


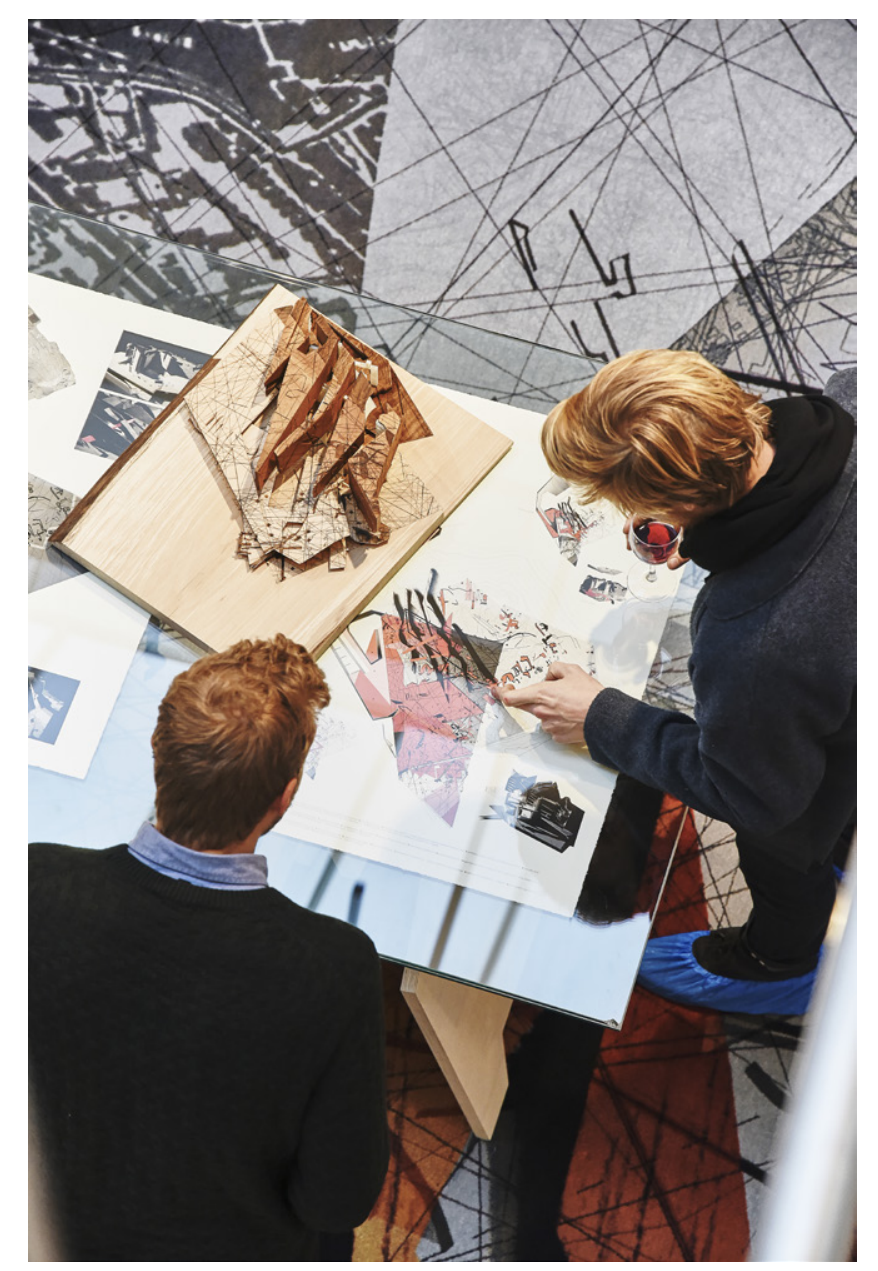

Fig. 09

Metis: Mark Dorrian and Adrian Hawker, On the Surface [Egyptian Museum, Cairo]

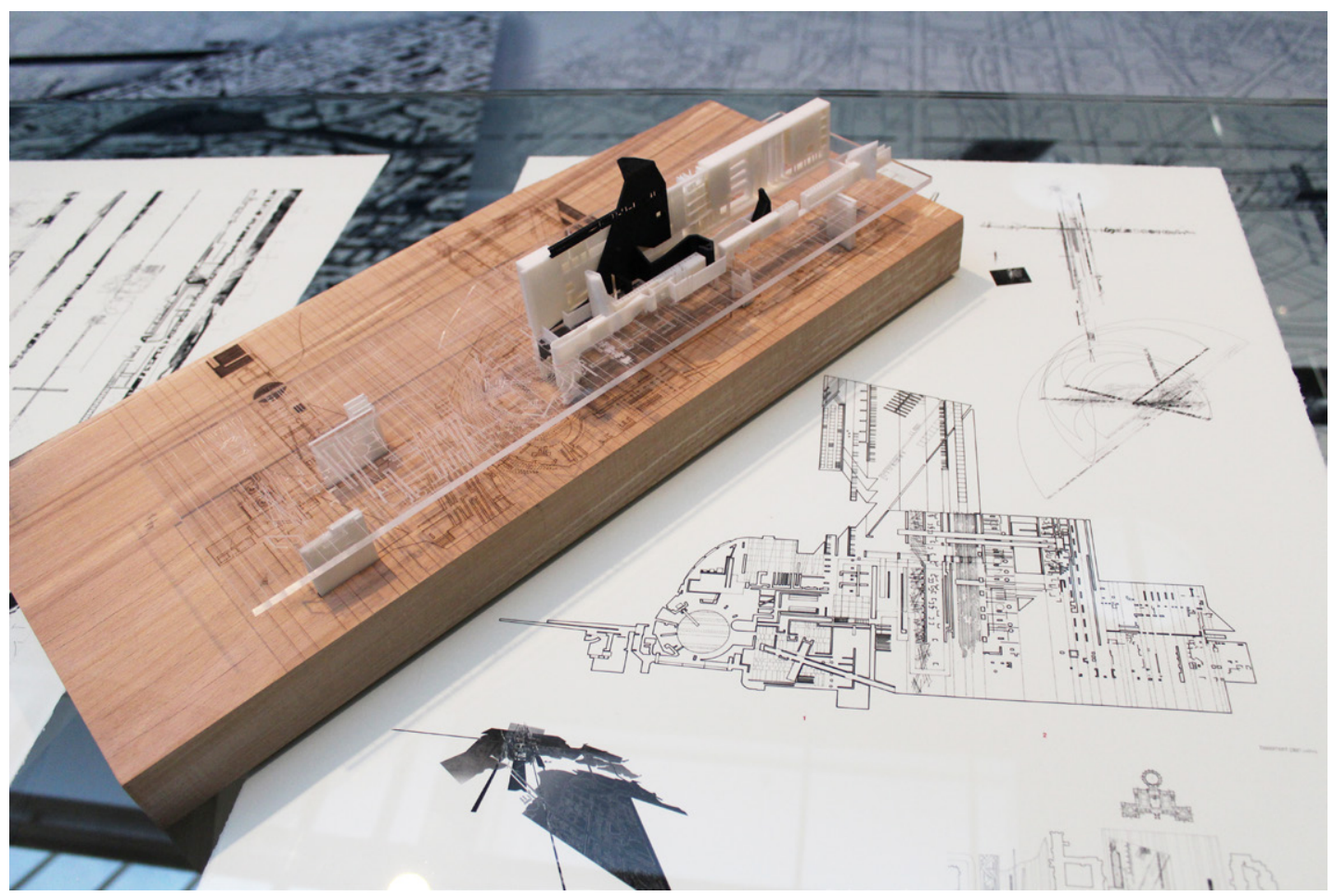

Fig. 10

Metis: Mark Dorrian and Adrian Hawker, On the Surface [Micro-urbanism, Parliament Hill, Ottawa, Canada] 


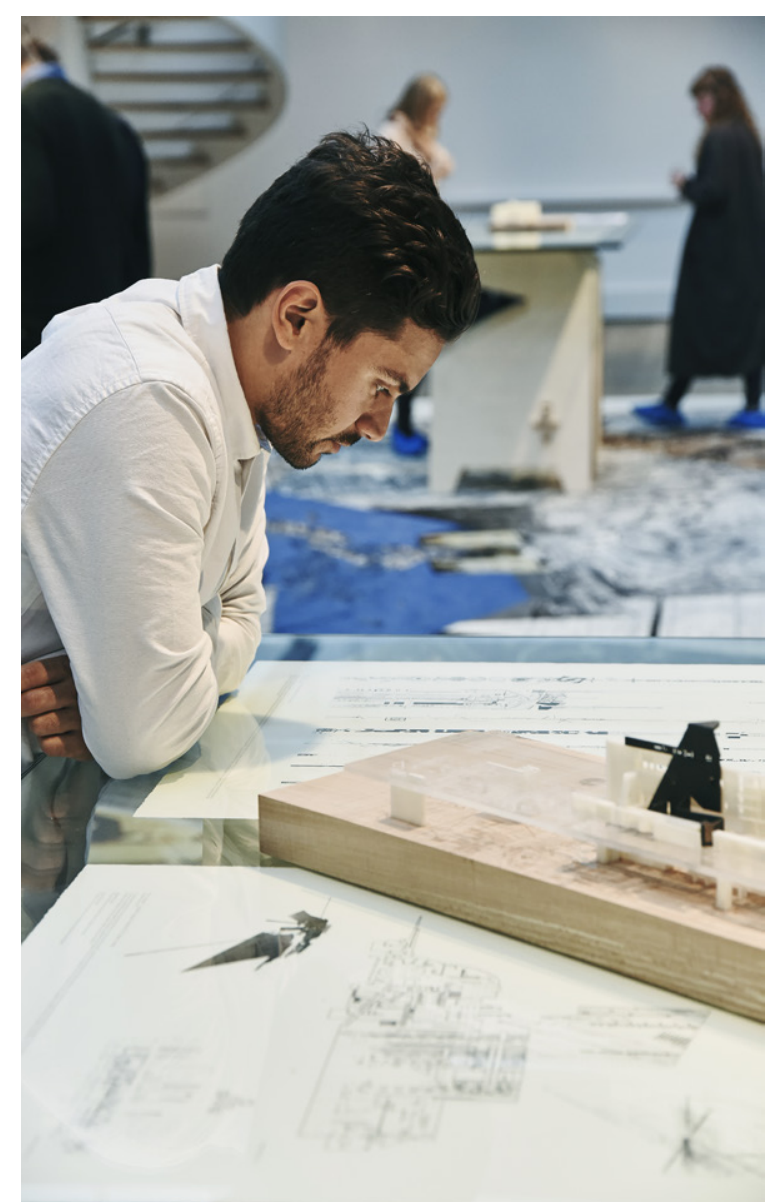

Fig. 11

Metis: Mark Dorrian and Adrian Hawker, On the Surface [Micro-urbanism, Parliament Hill, Ottawa, Canada]

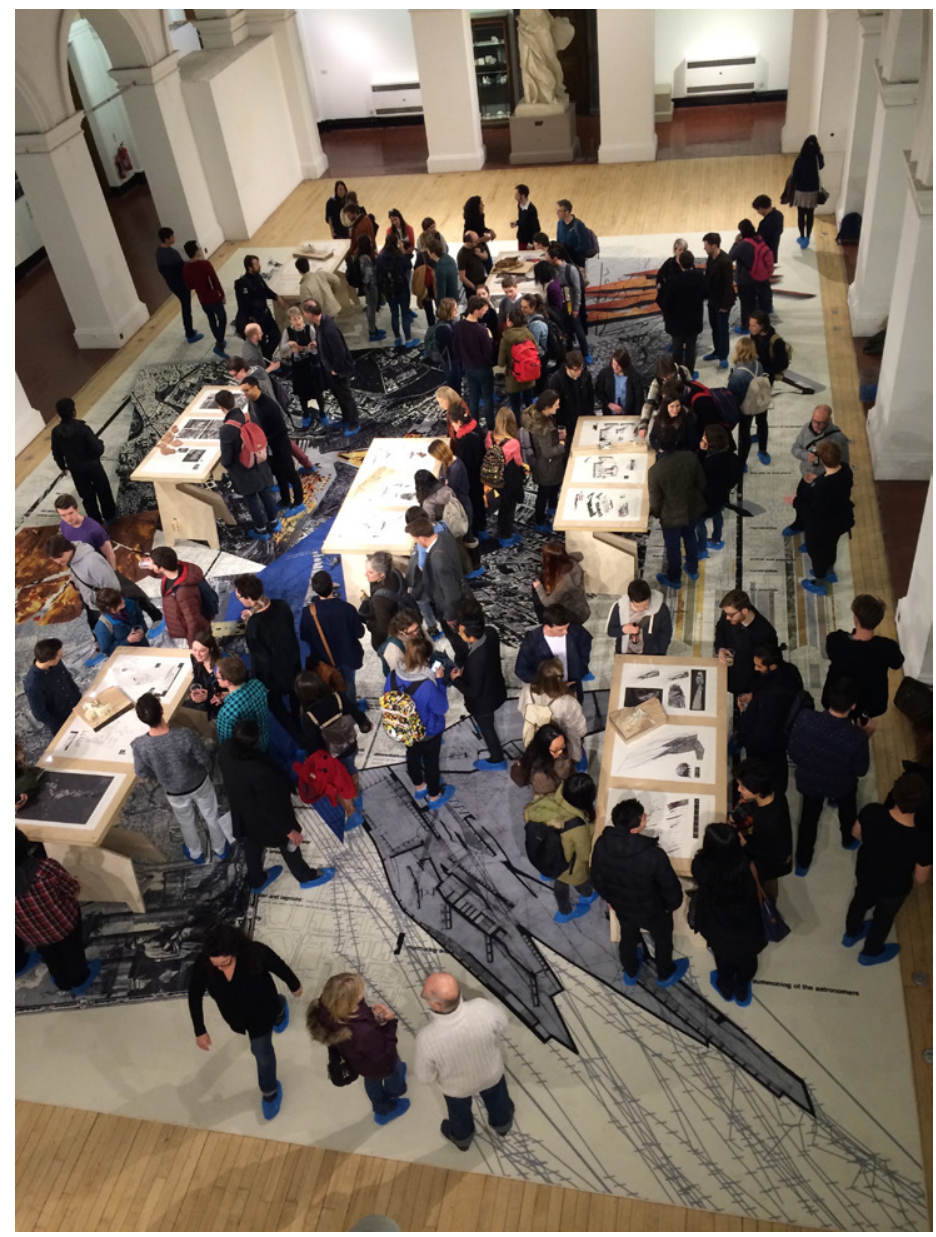

Fig. 12

Metis: Mark Dorrian and Adrian Hawker, On the Surface [Installation in Sculpture Court, Edinburgh College of Art] 


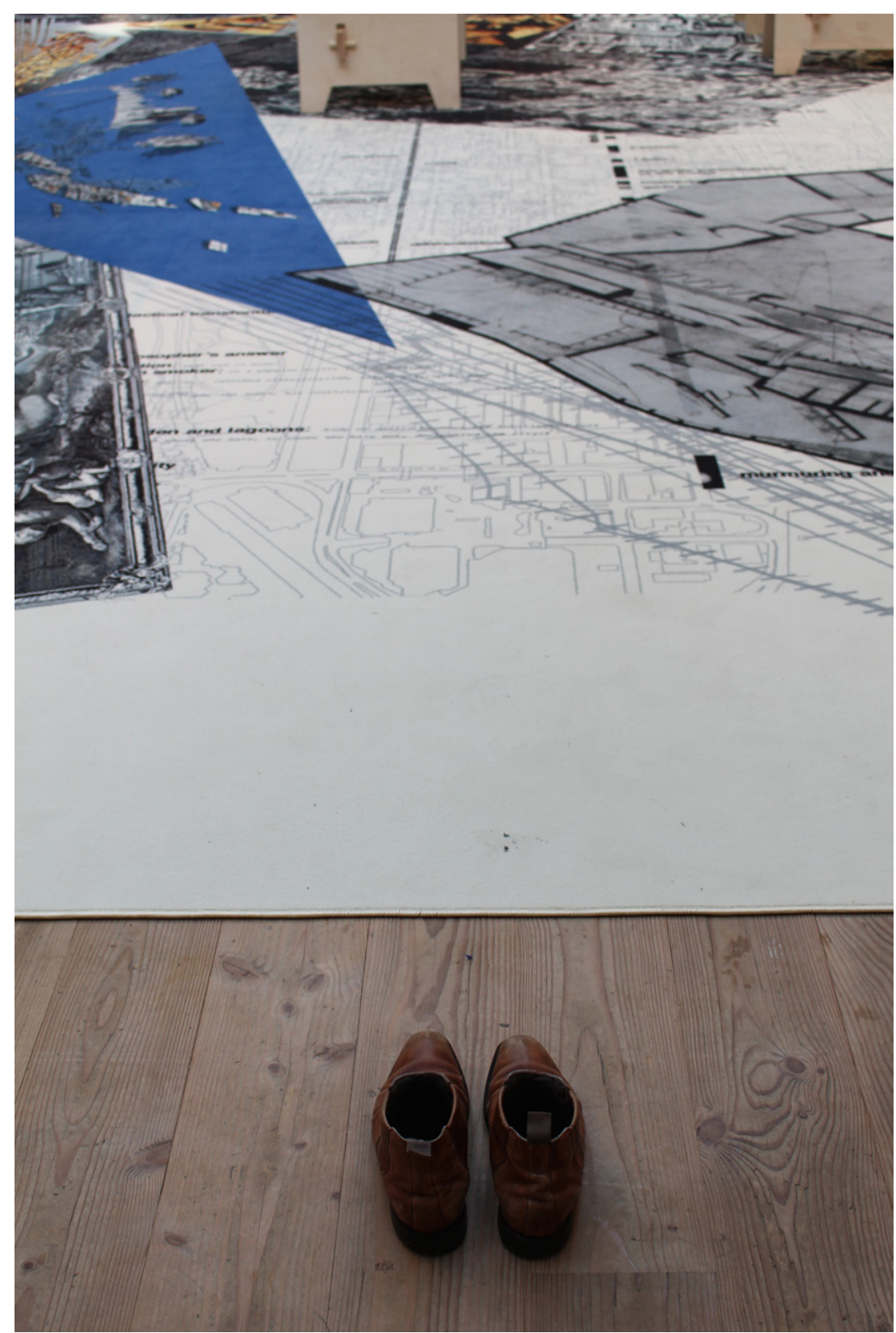

Fig. 13

Metis: Mark Dorrian and Adrian Hawker, On the Surface [Edge of floor drawing with boots]

Photo credits:

$\begin{array}{ll}\text { Figs. 03, 10 } & \text { Mark Dorrian } \\ \text { Figs. 04- 9, 11 } & \text { Gert Skærlund Andersen } \\ \text { Fig. 12 } & \text { Adrian Hawker } \\ \text { Fig. 13 } & \text { Ella Chmielewska }\end{array}$




\section{References}

Carbone, C. (2015). Expanding surfaces”, Architecture Research Quarterly, 19(2): 107-109, 107.

Latour, B. (2004). Why has critique run out of steam? From matters of fact to matters of concern, Critical Inquiry 30:225-248; 232. 